\title{
Synthesis of 1,6-Hexandiol, Polyurethane Monomer Derivatives via Isomerization Metathesis of Methyl Linolenate
}

\author{
Ervin Kovács, ${ }^{1}$ Gábor Turczel, ${ }^{1}$ Lili Szabo,,${ }^{1}$ Réka Varga, ${ }^{1}$ Imre Tóth, ${ }^{l}$ Paul T. Anastas, ${ }^{2 *}$
}

$$
\text { Robert Tuba, }{ }^{l, * *}
$$

${ }^{1}$ Institute of Materials and Environmental Chemistry, Research Centre for Natural Sciences, Hungarian Academy of Sciences Magyar tudósok körútja 2., 1519 Budapest, P.O. Box 286. ${ }^{2}$ Center for Green Chemistry and Engineering, Yale University, New Haven, Connecticut 06511, USA.

*Email: tuba.robert@ttk.mta.hu, paul.anastas@yale.edu

KEYWORDS: Conjugated olefins, cross-metathesis, renewable feedstock, isomerization, ruthenium 
ABSTRACT. Cross metatheses of tung oil, a non-edible vegetable oil and $\alpha$-eleostearic acid $((9 Z, 11 E, 13 E)$-octadeca-9,11,13-trienoic acid, ESA) methyl ester (1), obtained from tung oil containing the same highly unsaturated, conjugated double bonds, have been carried out with cis1,4-diacetoxy-2-butene (2) using Hoveyda-Grubbs (3-HG2), Grubbs second or third generation catalysts (3-G2 or 3-G3). The reactions followed by Pd/C-catalyzed hydrogenation, give methyl 11-acetoxyundecanoate (4) as a polyester raw material, 1,6-diacetoxy-hexane (5) as a precursor of 1,6-hexanediol (6) polyurethane monomer and heptyl acetate as a flagrance (7) in 53-99\% yields after Pd/C-catalyzed hydrogenation. The one-pot isomerization metathesis of $\alpha$-linolenic acid $((9 Z, 12 Z, 15 Z)-9,12,15$-octadecatrienoic acid, ALA) methyl ester (7) using $\mathbf{2}$ as cross coupling agent, $\mathrm{RuHCl}(\mathrm{CO})\left(\mathrm{PPh}_{3}\right)_{3}$ (9) as isomerization and 3-G2 as metathesis catalyst followed by $\mathrm{Pd} / \mathrm{C}$ catalyzed hydrogenation leads also to the formation of $\mathbf{5}$ and the homologs of $\mathbf{4}$ and $\mathbf{7}$ in reasonable yield. Thus, in the latter approach, the key step of the synthesis of $\mathbf{5}$ is the one-pot isomerization of the isolated double bonds of $\mathbf{7}$ into conjugated ones along the fatty acid chain in combination with a subsequent cross-metathesis by using cross-coupling agent 2 .

The conversion of unsaturated fatty acid esters via olefin metathesis including self and cross metathesis has been an emerging research area in the last decade..$^{1-4}$ Alternative routes have already been demonstrated from these renewable chemical resources to a wide range of chemicals including polyester and polyamide monomers. ${ }^{1-7}$ However, conjugated fatty acids which, are produced on a vast scale by the oleochemical industry ${ }^{8}$ have not been investigated as potential resources for metathesis reactions yet. It is known that the metathesis reaction of conjugated olefins is generally less efficient comparing to polyunsaturated systems containing 
isolated double bonds and often requires high catalyst loading (5 - $15 \mathrm{~mol} \%)$ and vigorous reaction conditions..$^{910}$

The 1,6-hexanediol (6) is used in several polymer syntheses including polyurethanes, acrylates, unsaturated polyesters, coatings and plasticizers. The market of $\mathbf{6}$ is estimated at USD 730 million in 2016 and is projected to grow over 1 billion USD by $2021 .{ }^{11}$ Rennovia Inc. has started piloting a renewable, sugar-based production of $\mathbf{6}$ this year. ${ }^{12}$ However, the synthesis of this important plastic building block from unsaturated fatty acids such as $\alpha$-eleostearic or $\alpha-$ linolenic acid has not been reported yet.

Algae oils, especially from microalgae with high lipid concentration have incredible potential as green and sustainable material ${ }^{13,14}$ and energy sources.${ }^{15,16}$ Algae oil from microalgae or as also called oilgae can have 10-30 times higher yield per hectare than usual oil crops. ${ }^{17,18}$ Algae as photosynthetic organisms generate mainly proteins, lipids, carbohydrates and small amounts of nucleic acids. ${ }^{19,20}$ The lipids, which are the most important for biofuel manufacture, contain isoprenoids, triacylglycerides (TGAs) and phospholipids. ${ }^{21-23}$ Some of the algae contains up to $40-50 \%$ unsaturated fatty acids ${ }^{24,25}$ (Scheme 1), which can be readily obtained from TGAs or phospholipids by hydrolysis or transesterification ${ }^{26}$ respectively. Algae oils also contain vital omega-3 fatty acids, such as docosahexaenoic acid (DHA, $\mathrm{x}=1 ; \mathrm{y}=5 ; \mathrm{z}=1$ ) and eicosapentaenoic acid (EPA, $\mathrm{x}=1 ; \mathrm{y}=4 ; \mathrm{z}=1)$, which are involved in human physiology. ${ }^{27}$ ALA, $\alpha$-linolenic acid $(x=6 ; y=2 ; z=1)$ can also be found in some plant oils in vast amount as discussed below (Scheme 1).

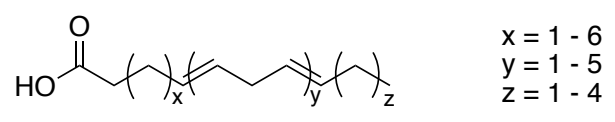


Scheme 1. General structure of polyunsaturated fatty acids produced by algae.

Among others, the presence of highly unsaturated compounds causes a technical hurdle to produce biodiesel for the time being ${ }^{28,29}$ However, these fatty acids are ideal green stock material for the synthesis of sustainable chemicals via metathesis, such as innovative polymers, fine chemicals and pharmaceuticals, albeit their availability from algae is yet limited.

Fortunately, polyunsaturated fatty acids can also be found in some of the seed oils including tung oil and linseed oil (or flax oil). Tung oil contains about $80 \%$ of the valuable conjugated polyunsaturated $\alpha$-eleostearic acid, (ESA) (Scheme 2: methyl ester of ESA [1]), which is obtained from the kernels and the nuts of tung tree. The world production of tung oil was about $143 \mathrm{kt}$ in 1970 and was projected to reach $200 \mathrm{kt}$ by $1980 .^{30}$ Instead, the production dropped back to $90 \mathrm{kt}$ by the end of 90 's and stayed at that level up to date, because of the persisting cultivation in China. ${ }^{31}$ Farming of tung tree plunged or ceased in many countries because of its weak agronomic attributes as compared to other crop plants. The reasons for this are that the tung tree requires warm climate, high humidity and had proven to be an aggressive sort causing irritation to many. ${ }^{32}$ Thus, current research focuses on obtaining of the key intermediate of the tung tree instead of growing the tree itself. For example, ESA, 1 can be generated by genetic engineering of crop plants such as soybean ${ }^{33,34}$ or by metabolic engineering of other crop oils. ${ }^{35}$

As presented in this communication, derivatives of $\mathbf{1}$ can also be obtained by the isomerization of 8 . The linseed contains about $41 \%$ of oil including $57 \%$ of ALA. ${ }^{36}$ The global production of linseed oil was around $580 \mathrm{kt}$ in $2014 .{ }^{37}$ This important compound, ALA can also 
be found in many other crops including that of the sea buckthorn, which has an increasing reputation and growing area. ${ }^{38,39}$

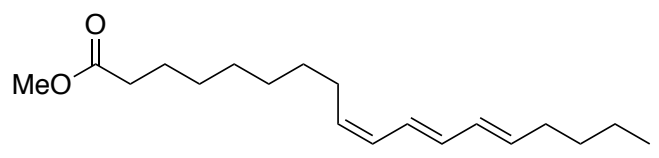

1

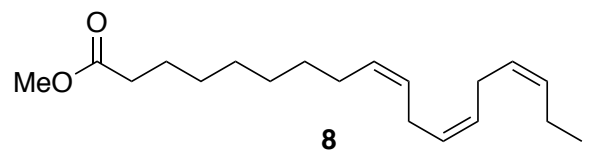

Scheme 2. Chemical structures of $\alpha$-eleostearic (1) acid and $\alpha$-linolenic acid (8) methyl ester.

The application of olefin metathesis on the field of green chemistry, especially in oleochemistry is emerging. ${ }^{40,41}$ The most active and widely used catalysts are molybdenum- ${ }^{42}$ or ruthenium-based systems. ${ }^{43}$ The molybdenum-based systems are sometimes more active than the ruthenium systems, however, they often suffer from low functional group tolerance, high air and moisture sensitivity. Therefore, their industrial and large-scale applications are often limited. Comparing to this, the ruthenium catalyst systems are much more robust and have higher functional group tolerance (i.e. remains active toward conjugated systems and tolerates $\mathrm{OH}$ functionalities $)^{44}$ (Scheme 3). Nowadays many metathesis catalysts have become commercially available and are widely used in industrial applications. ${ }^{45-50}$

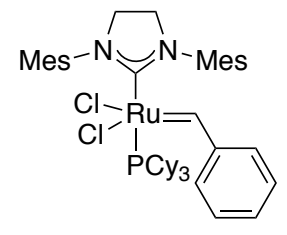

3-G2

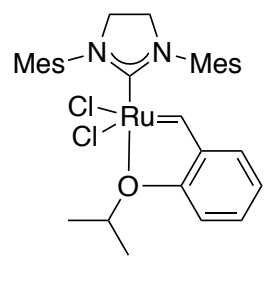

3-HG2

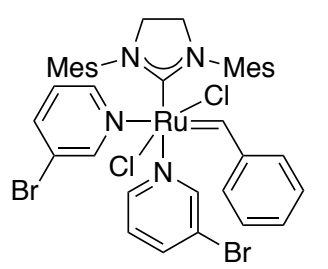

3-G3

Scheme 3. Grubbs catalysts tested for cross-metathesis of $\mathbf{1}$. 
A unique methodology reported here combines the one-pot isomerization and crossmetathesis of polyunsaturated fatty acid derivatives to obtain commercially relevant, high value added chemicals. The cross-metathesis of $\mathbf{1}$ has recently been investigated using cis-stilbene as model cross-coupling agent indicating the formation of a species containing mono $=\mathrm{CH}-\mathrm{CH}=$ building block units in reasonable yields. ${ }^{51}$ Following these preliminary studies our attention turned to the cross-metathesis of $\mathbf{1}$ with cis-1,4-diacetoxy-2-butene, $\mathbf{2}$ to obtain the unsaturated derivative - hexa-2,4-diene-1,6-diyl diacetate (10) - of 1,6-hexandiol diacetate (5), the precursor of 1,6-hexanediol (6). Some preliminary catalytic tests have also been carried out with nonacylated species, however, due to the relatively fast catalyst decomposition low conversion and only traces of target compound formation were observed. Compound $\mathbf{2}$ can be readily synthetized from allyl alcohol via olefin metathesis. Allyl alcohol is considered as a renewable material as it can be obtained from glycerol. ${ }^{52}$ Although, allyl acetate and $\mathbf{2}$ have already been investigated as active cross-coupling agent giving $\alpha, \varpi$-diffunctional substrates such as methyl 11-acetoxyundec-9-enoate (11) the precursor of 11-hydroxynonanoic acid (13), polyester monomer in oleochemistry, ${ }^{53,54}$ their metathesis with conjugated fatty acid based feedstocks leading to the formation of high value added polyurethane monomer $\mathbf{6}$ have not been examined yet. It was found that the $\mathrm{CM}$ reaction of $\mathbf{1}$ at room temperature in the presence of nine-fold excess (three-fold excess per double bond) of 2 using 1-5 mol\% catalyst (3-HG2, 3-G2 or 3-G3) loading $(0.33-1.66 \mathrm{~mol} \%$ per double bond of $\mathbf{1})$ the formation of methyl 11-acetoxyundec-9enoate (11), 1,6-diacetoxy-2,4-hexadiene 10 and hept-2-en-1-yl acetate (12) were observed. Due to some undesired side reactions - mainly isomerization ${ }^{55}$ - some homolog analogues of $\mathbf{1 1}$ and 12 were also observed especially in the reactions conducted at elevated reaction temperature. The reaction mixtures were hydrogenated off in one-pot by $\mathrm{Pd} / \mathrm{C}$ using atmospheric hydrogen 
pressure to obtain methyl 11-acetoxy-undecanoate, 4, 1,6-diacetoxy-hexane, 5 and heptyl acetate, $\mathbf{7}$ in reasonable yields referenced to $\mathbf{1}$ (99\%, 53\% and 94\%, respectively) (Scheme 4). Beside the mass spectra analysis of the reaction products the formation of the target compounds was also confirmed by spiking technique. As the ultimate goal is the development of a convenient, one-pot synthesis of $\mathbf{5}$, the metathesis reaction mixture was always followed by hydrogenation and the configurational isomers of the unsaturated intermediates were not investigated in detail. However, based on the interim GC-MS data analysis, $80 \%$ trans and $20 \%$ cis bond formation is suspected, which is align with the ratio of the configurational isomers reported in the literature for metathesis reaction products using catalysts $3{ }^{56,57}$ The slightly lower yield of 5 can be explained by the presence of octane-1,8-diyl diacetate $\left(\mathbf{5}^{*}\right)$, which can form via hydrogenation from the unreacted, intermediate the hexa-1,3,5-triene-1,6-diyl diacetate $(10 *)$ homolog, being less active for metathesis (see Scheme 4). This is well aligned with the literature data indicating that due to the less nucleophilic nature of the conjugated double bonds, the metathesis reaction of these species is often cumbersome..$^{10}$ It is also supposed that some side reactions, including self-metathesis of $\mathbf{1 0}$ and $\mathbf{1 0 *}$ giving non-soluble polyacetylene species may also be responsible for the reduced yield of 5 (and $5^{*}$ ) comparing to 4 and 7 . 


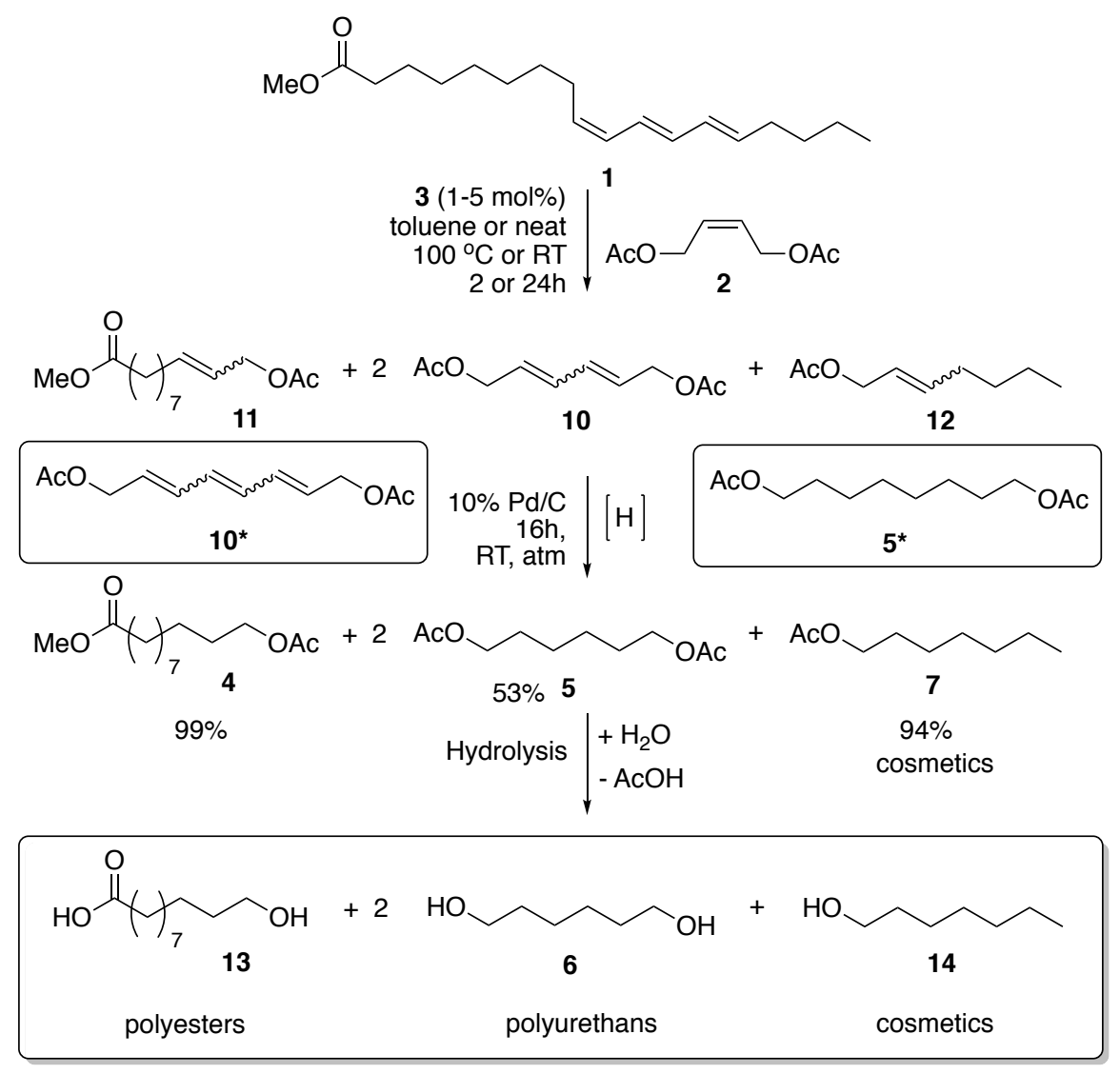

Scheme 4. Synthesis of polyester and polyurethane monomers via cross-metathesis (CM) of 1 and 2.

The activities of the catalysts (Scheme 3) have been investigated at room (RT, $24 \mathrm{~h}$ ) and elevated $\left(100^{\circ} \mathrm{C}, 2 \mathrm{~h}\right)$ temperatures in neat $\mathbf{2}$, using it in nine-fold excess (i.e. three-fold excess per double bond of 1). Interestingly, 3-HG2 showed the highest activity at RT, while at elevated temperature 3-G3 was the best catalyst (Table 1). The highest yield of 1,6-diacetoxy-hexane, $\mathbf{5}$ (53\%) was obtained by using catalyst $\mathbf{3 - G 3}$ at $100^{\circ} \mathrm{C}$ with complete conversion of the starting material 1. At elevated temperature, homologs of $\mathbf{1 1}$ were formed because of isomerization side reactions, which were not observed when the reactions were conducted at room temperature even for extended reaction times. The reactions carried out at lower catalyst loading ( 1 mol\%, 0.33 mol\% per double bond of $\mathbf{1}$ ) resulted in a slight decrease in the conversion of $\mathbf{1}(80 \%)$. However, 
the formation of $\mathbf{4}$ and $\mathbf{7}$ was significantly lowered (36\% and 23\%) and $\mathbf{5}$ was not detected at all in the reaction mixture (only $5^{*}$ in $6 \%$ ). Considering that the $\mathbf{1}$ contains three times more double bond than methyl oleate the optimal, 1.66 mol\% catalyst loading per double bound is wellaligned with the literature data reported for the cross-metathesis of methyl oleate and allyl acetate or $\mathbf{2}$, indicating that the optimal $\mathrm{Ru}$ metathesis catalyst loading is around $1-2 \mathrm{~mol} \%$ at similar reaction condition. ${ }^{54,58}$ 
Table 1. Yield of 4,5 and 7 referenced to 1 using different Grubbs catalyst systems (3). Neat (20 V/V\% toluene is used for the dissolution of the catalysts), catalyst loading: 5 mol\% (1.66 mol\% per double bond referenced to 1$),[1]=0.34 \mathrm{M}$; [2] = 4.1 M (12 mol equiv.); Condition A: $100^{\circ} \mathrm{C}, 2 \mathrm{~h}$; Condition B: RT, $24 \mathrm{~h}$.

\begin{tabular}{c|ccc|ccc}
\hline \multirow{2}{*}{ Catalyst } & \multicolumn{2}{|c|}{ Condition A (Yields \%) } & \multicolumn{3}{|c}{ Condition B (Yields \%) } \\
\cline { 2 - 7 } & $\mathbf{4}$ & $\mathbf{5}\left(\mathbf{5}^{*}\right)$ & $\mathbf{7}$ & $\mathbf{4}$ & $\mathbf{5}\left(\mathbf{5}^{*}\right)$ & $\mathbf{7}$ \\
\hline 3-G2 & 84 & $36(13)$ & 98 & 81 & $37(10)$ & 81 \\
3-HG2 & 99 & $21(11)$ & 88 & $\mathbf{9 9}$ & $\mathbf{4 9}(\mathbf{1 7})$ & $\mathbf{9 9}$ \\
$\mathbf{3 - G 3}$ & $\mathbf{9 9}$ & $\mathbf{5 3 ( 1 2 )}$ & $\mathbf{9 4}$ & 87 & $22(13)$ & 97 \\
\hline
\end{tabular}

The cross-metathesis of natural unsaturated triglycerides using $\mathbf{3}$ has already been reported. When the reaction is conducted in the presence of 2-butene using at $-5^{\circ} \mathrm{C}$, very high turnover number $\left(\mathrm{TON}>10^{4}\right.$ ) was observed. ${ }^{43}$ Based on the analogy, the synthesis of $\mathbf{5}, \mathbf{7}$ from the glycerol ester of ESA, 1 was carried out in neat, using 3-HG2 catalyst and crude, dried and pre-treated $^{59}$ tung oil as renewable feedstock at $15 \mathrm{~mol} \%$ catalyst $(1.66 \mathrm{~mol} \%$ per ESA double bond) loading. Cis-1,4-diacetoxy-2-butene, 2 was used in three-fold excess per double bond of the lipid. After metathesis, the reaction mixture was hydrogenated by $\mathrm{Pd} / \mathrm{C}$. The GC-MS analysis revealed the formation of compound $\mathbf{5}$ and $\mathbf{7}$ as major products in $26 \%$ and $99 \%$ yields, respectively, including $5^{*}$ in 14\%. Increasing the excess of 2 had no impact on the overall yield of 5. These experiments clearly indicate the feasibility of the synthesis of 1,6-hexanediol derivatives, 5 via direct CM of crude tung oil and 2 using 3-HG2 catalysts (Scheme 5). 


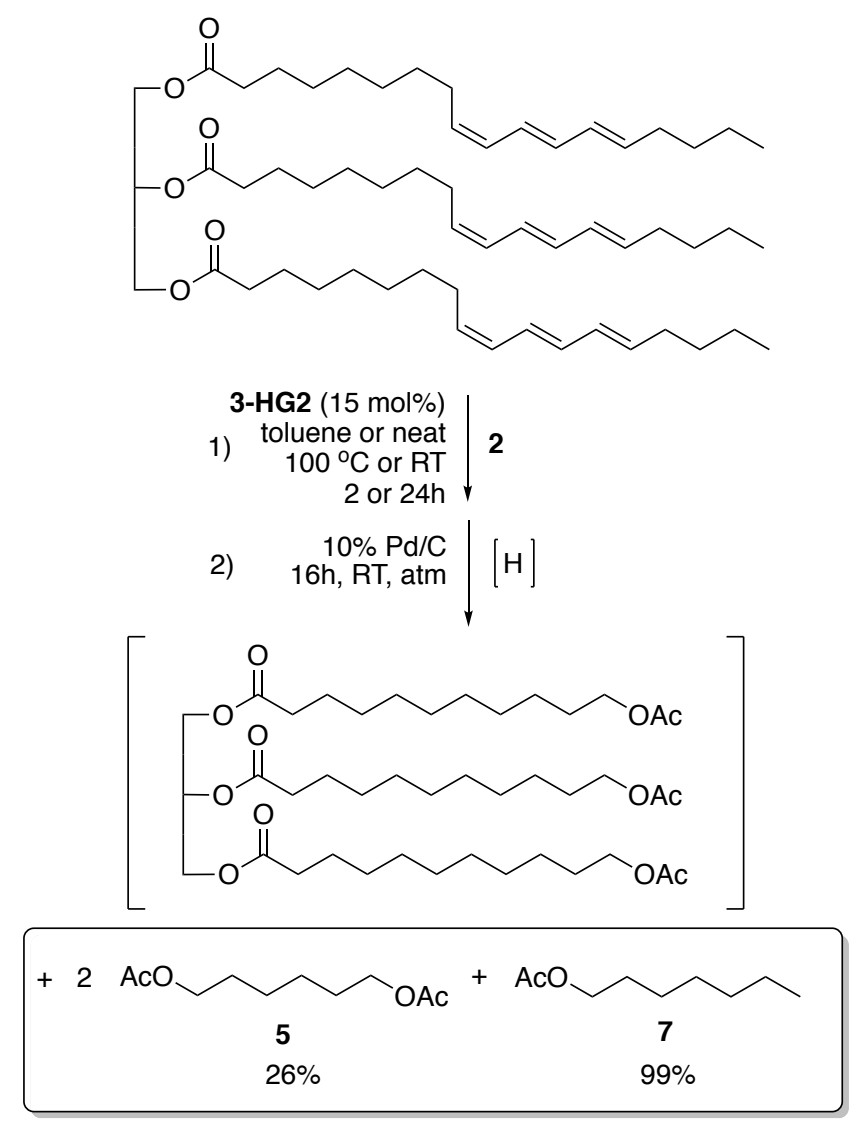

Scheme 5. Synthesis of 5 and 7 via CM of crude tung oil with $\mathbf{2}$ (leading also to $\mathbf{5}^{*}$ in $14 \%$ yield)

Following these studies our attention turned to the possibility of a ruthenium doublecatalyzed in situ synthesis of the 1,6-diol precursor, $\mathbf{5}$ and homologs of $\mathbf{4}$ and $\mathbf{7}$ using methyl linoleate, $\mathbf{8}$ as crude starting material via a one-pot isomerization and cross-metathesis, called isomerization metathesis reaction. The combined isomerization and metathesis of olefins ${ }^{60,61}$ has been reported for the synthesis of homologs of unsaturated compounds from oleo chemicals ${ }^{62,63}$ and also quite common in petro chemistry in OCT (Olefin Conversion Technology). Although some data for linoleic acid derivatives containing two isolated double bonds has been reported ${ }^{64}$ the isomerization metathesis of three isolated double bonds containing methyl linoleate 8 has not been investigated yet. 
First, the Ru-catalyzed isomerization of $\mathbf{8}$ has been investigated using $\operatorname{RuHCl}(\mathrm{CO})\left(\mathrm{PPh}_{3}\right)_{3}$ (9) catalyst. According to in-situ ${ }^{1} \mathrm{H}$ NMR investigation, it could be concluded that the isolated double bonds of $\mathbf{8}$ can be readily isomerized into conjugated ones at relatively low catalyst loading (0.5 mol\%) giving a mixture of compounds having similar chemical structures (spectra 1-7) - with random configurational isomers - like that of $\mathbf{1}$ (spectra 8, Figure 1).
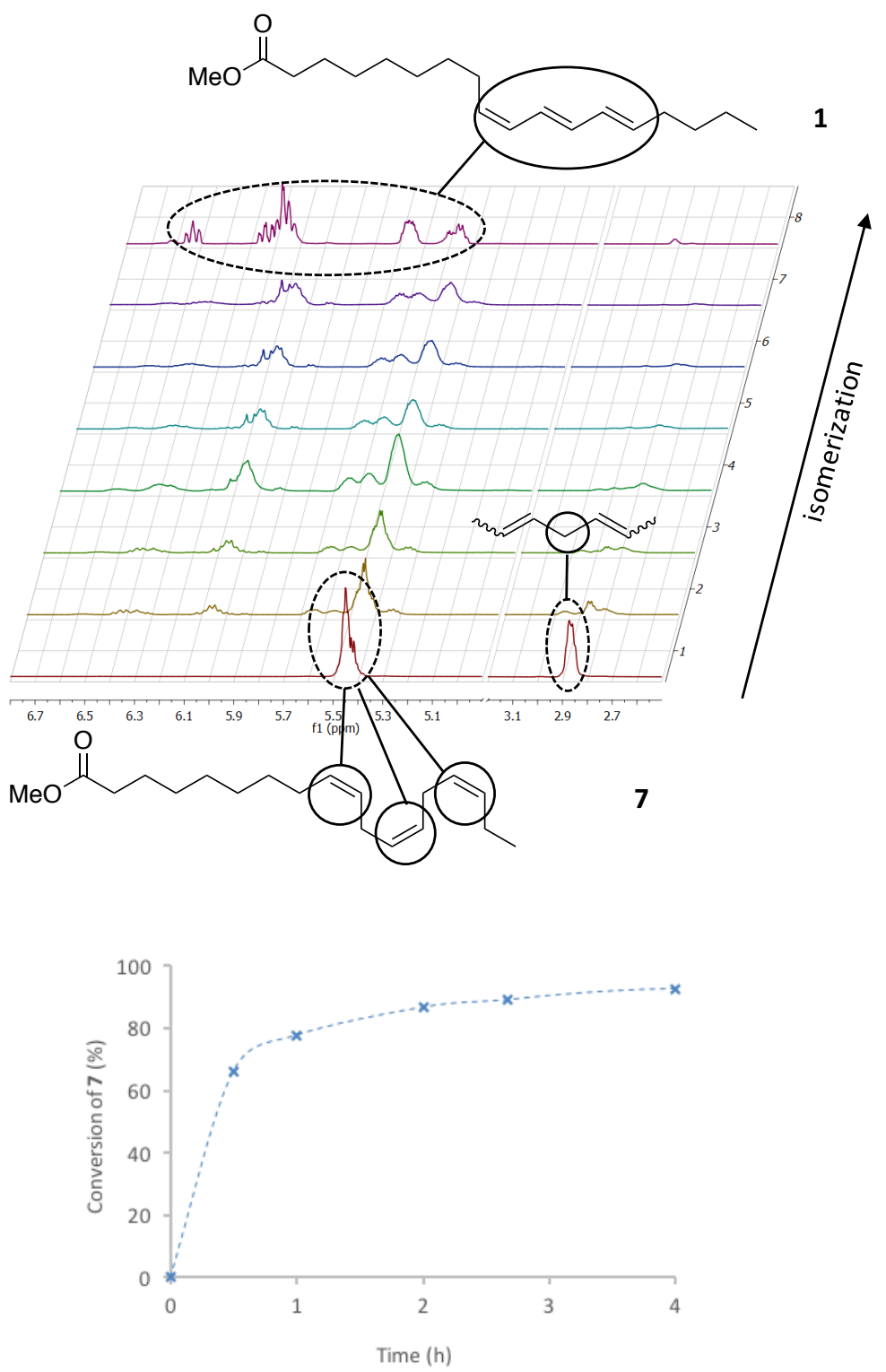

Figure 1. Top: In-situ stacked ${ }^{1} \mathrm{H}$ NMR spectra of the isomerization reaction mixture (spectra 17) of methyl ester of ALA, 8 (toluene- $d_{8}, 9(0.5 \mathrm{~mol} \%), 90^{\circ} \mathrm{C},[8]=0.947 \mathrm{M}$; [9] $\left.=4.51 \mathrm{mM}\right)$ 
and ${ }^{1} \mathrm{H}$ NMR of $\mathbf{1}$ (spectra 8). Bottom: conversion of $\mathbf{8}$ (disappearance of $-\mathrm{CH}_{2}-$ proton signal at $2.85 \mathrm{ppm})$ versus reaction time.

The disappearance of the $=\mathrm{CH}-\mathrm{CH}_{2}-\mathrm{CH}=$ signal at $2.85 \mathrm{ppm}$ and the downfield shift of the $=\mathrm{CH}$ - from 5.5 to $6.5 \mathrm{ppm}$ has clearly indicated the formation of conjugated systems (Figure 1, top). ${ }^{65}$ Ninety percent conversion of the starting material (crude mixture of $\mathbf{8}$ ) was observed after two hours of reaction time (see Figure 1, bottom).

The one-pot isomerization and cross-metathesis using $\mathbf{8}$ gave similar reaction mixture composition than that of the metathesis of $\mathbf{1}$. As expected, the formation of $\mathbf{5}$ in $44 \%$ - and $\mathbf{5}^{*}$ in $17 \%$ yield (as referenced to $\mathbf{8}$ ) - and a statistical distribution of $\mathbf{4}$ and $\mathbf{6}$, and their homologs were observed using similar catalyst systems (Figure 2). The statistical distribution of $\mathbf{4}$ and $\mathbf{7}$ can be explained by the random migration (isomerization) of the isolated double bounds over the fatty acid chain to form a thermodynamically favored conjugated system. As it can be clearly seen in Figure 2, the major reaction product is $\mathbf{5}$. The homologs of $\mathbf{7}$ contain C4-C13 acylated alcohols, meanwhile the homologs of 4 involve C7-C14 species. The $n=4(\mathrm{C} 7-\mathrm{Ac})$ corresponds to 4 and $\mathrm{m}=7$ (C11-Ac) to $\mathbf{7}$, respectively. There was neither $\mathbf{1}$ nor $\mathbf{8}$ remaining starting material detected after metathesis. Compound $\mathbf{5}$ as major reaction product is indicated on the chromatogram (Figure 2, top). 

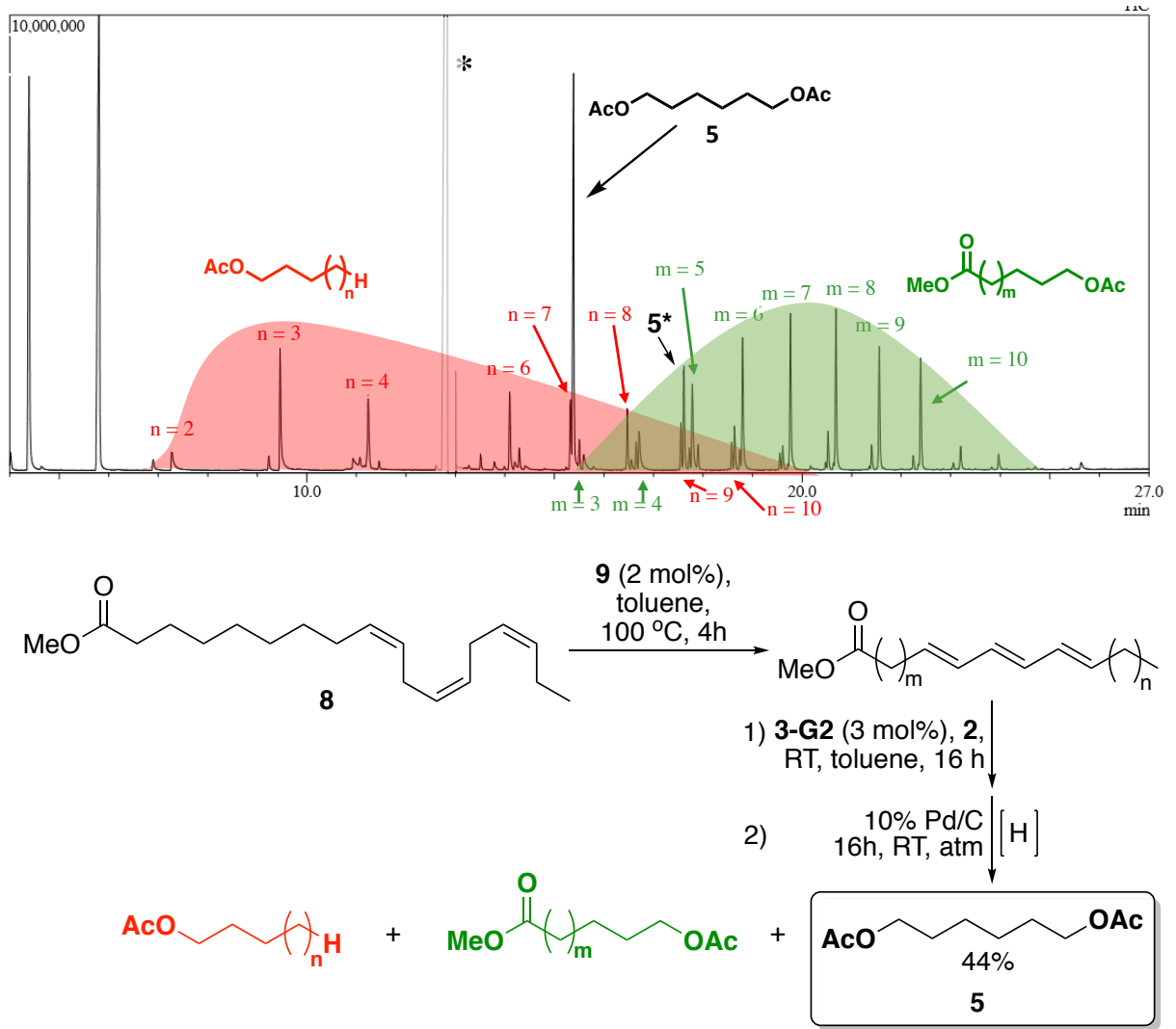

Figure 2. TIC of the reaction mixture of the one-pot isomerization metathesis and hydrogenation of 8. (*The CM agent, 2 is also visible as a major peak at $12.7 \mathrm{~min}$.) (Yield is referenced to $\mathbf{8}$ )

\section{Conclusions}

The synthesis of polyester and polyurethane monomers including 1,6-diacetoxy-hexane (5), acetoxy-alkanoates, 4 and 1-heptyl acetate (7) using polyunsaturated conjugated feedstock has been demonstrated. ESA, $\alpha$-eleostearic acid methyl ester, $\mathbf{1}$ is an ideal feedstock to produce value added chemicals such as 4,5 and 7, polymer raw materials using Grubbs (3) catalyst systems. The synthesis of $\mathbf{5}$ and the homologs of $\mathbf{4}$ and $\mathbf{7}$ is also possible using ALA, $\alpha$-linolenic acid methyl ester (8) via ruthenium catalysed one-pot isomerization and cross metathesis reaction. 
It has been shown that the synthesis of some commercially available so far petrochemical based chemicals is feasible from renewable feedstocks. This chemical procedure makes the synthesis of polyurethane and polyester monomers possible using a wide range of polyunsaturated fatty acids of different origin containing conjugated or isolated double bonds. The combination of one-pot isomerization and cross-metathesis reactions of polyunsaturated fatty acid feedstocks (either vegetable oil or algae oil based) provides new alternatives for the replacement of fossil based materials into carbon dioxide neutral, sustainable ones.

\section{ASSOCIATED CONTENT}

\section{Supporting Information}

The Supporting Information is available free of charge on the ACS Publications website at DOI:

${ }^{1} \mathrm{H}$ NMR spectra and GC-MS data, experimental details of isomerization, crossmetathesis and hydrogenation reactions, materials and methods, (PDF)

\section{AUTHOR INFORMATION}

\section{Corresponding Authors}

*Dr. Robert Tuba. Tel: +36-20-980-4527. E-mail: tuba.robert@ttk.mta.hu.

\section{Author Contributions}

The manuscript was written through contributions of all authors. All authors have given approval to the final version of the manuscript.

\section{Notes}


The authors declare no competing financial interest.

\section{ACKNOWLEDGMENT}

We thank the Hungarian Academy of Sciences and National Research, Development and Innovation Office (NKFIH) for financial support under Grant Nos. OTKA NN 117986.

\section{DEDICATION}

$\ddagger$ Dedicated to a former supervisor and longtime friend, István Horváth, on the occasion of his 65th birthday.

\section{REFERENCES}

(1) Lunt, J.; et al., Marketplace opportunities for integration of biobased and conventional plastics, Agricultural Utilization Research Institute, Minnesota, USA, 2014.

(2) Miao, X.; Dixneuf, P. H.; Fischmeister, C.; Bruneau, C. A green route to nitrogencontaining groups: the acrylonitrile cross-metathesis and applications to plant oil derivatives. Green Chem., 2011, 13, 2258-2271, DOI: 10.1039/C1GC15377C

(3) Miao, X.; Fischmeister, C.; Dixneuf, P. H.; Bruneau, C.; Dubois, J.-L.; Couturier, J.-L. Polyamide precursors from renewable 10-undecenenitrile and methyl acrylate via olefin cross-metathesis. Green Chem., 2012, 14, 2179-2183, DOI: 10.1039/C2GC35648A

(4) Malacea, R.; Fischmeister, C.; Bruneau, C.; Dubois, J.-L.; Couturier, J.-L.; Dixneuf, P. H. Renewable materials as precursors of linear nitrile-acid derivatives via crossmetathesis of fatty esters and acids with acrylonitrile and fumaronitrile. Green Chem., 2009, 11, 152-155, DOI: 10.1039/B816917A 
(5) Biermann, U., Bornscheuer, U., Meier, M. A. R., Metzger, J. O., Schäfer, H. J. Oils and fats as renewable raw materials in chemistry. Angew. Chem. Int. Ed. 2011, 50, 38543871, DOI: 10.1002/anie.201002767

(6) Meier, M. A.; Metzger, J. O.; Schubert, U. S. Plant oil renewable resources as green alternatives in polymer science. Chem. Soc. Rev., 2007, 36, 1788-1802, DOI: 10.1039/B703294C

(7) Noordover, B. A. J. Polyesters, polycarbonates and polyamides based on renewable resources. In Renewable polymers: synthesis, processing, and technology; Mittal, V., Ed.;, John Wiley \& Sons, Inc., Hoboken, NJ, USA., 2011.

(8) Philippaerts, A.; Goossens, S.; Jacobs, P. A.; Sels, B. F. Catalytic production of conjugated fatty acids and oils. ChemSusChem, 2011, 4, 684-702, DOI: $10.1002 /$ cssc. 201190022

(9) Murelli, R. P.; Snapper, M. L. Ruthenium-catalyzed tandem cross-metathesis/Wittig olefination: generation of conjugated dienoic esters from terminal olefins. Org. Lett., 2007, 9, 1749-1752, DOI: 10.1021/o1070445t

(10) Balla, Á.; Al-Hashimi, M.; Bazzi, H. S.; Tuba, R. Ruthenium-catalyzed metathesis of conjugated polyenes. ChemCatChem. 2016, 8, 2865-2875, DOI: 10.1002/cctc.201600479

(11) 1,6-Hexanediol Market worth 1,042.1 Million USD by 2021, retrieved July 9, 2017, http://www.marketsandmarkets.com/PressReleases/1-6-hexanediol-hdo.asp

(12) Rennovia enters piloting stage of its bio-based 1,6-hexanediol process, 2017, http://www.rennovia.com 
(13) Roesle, P.; Stempfle, F.; Hess, S. K.; Zimmerer, J.; Bártulos, C. R.; Lepetit, B.; Eckert, A.; Kroth, P. G.; Mecking, S. Synthetic polyester from algae oil. Angew. Chem. Int. Ed. 2014, 53, 6800-6804, DOI: 10.1002/anie.201403991

(14) de Espinosa, L. M.; Meier, M. A. R. Plant oils: the perfect renewable resource for polymer science?! Eur. Polym. J. 2011, 47, 837-852, DOI: 10.1016/j.eurpolymj.2010.11.020

(15) Ajjawi, I.; Verruto, J.; Aqui, M.; Soriaga, L. B.; Coppersmith, J.; Kwok, K.; Peach, L.; Orchard, E.; Kalb, R.; Xu, W.; Carlson, T. J.; Francis, K.; Konigsfeld, K.; Bartalis, J.; Schultz, A.; Lambert, W.; Schwartz, A. S.; Brown, R.; Moellering, E. R. Lipid production in Nannochloropsis gaditana is doubled by decreasing expression of a single transcriptional regulator. Nat. Biotechnol., 2017, 35, 647-652, DOI: 10.1038/nbt.3865

(16) Juneja, A.; Ceballos, R. M.; Murthy, G. S. Effects of environmental factors and nutrient availability on the biochemical composition of algae for biofuels production: a review. Energies 2013, 6, 4607-4638, DOI: 10.3390/en6094607

(17) Schlagermann, P.; Göttlicher, G.; Dillschneider, R.; Rosello-Sastre, R. Posten, C. Composition of algal oil and its potential as biofuel. J. Combust., 2012, 2012, Article ID 285185, DOI: $10.1155 / 2012 / 285185$

(18) Pienkos, P. T. The Potential for biofuels from algae. Algae Biomass Summit, San Fransisco, CA, November 15, 2007.

(19) Algal Chemical Composition, retreived July 9, 2017, http://www.oilgae.com/algae/comp/comp.html 
(20) Tibbetts, S. M.; Milley, J. E.; Lall, S. P. Chemical composition and nutritional properties of freshwater and marine microalgal biomass cultured in photobioreactors. J. Appl. Phycol., 2015, 27, 1109-1119, DOI: 10.1007/s10811-014-0428-x

(21) Hu, Q.; Sommerfeld, M.; Jarvis, E.; Ghirardi, M.; Posewitz, M.; Seibert, M.; Darzins, A. Microalgal triacylglycerols as feedstocks for biofuel production: perspectives and advances. Plant J., 2008, 54, 621-639, DOI: 10.1111/j.1365-313X.2008.03492.x

(22) Schouten, S.; Breteler, W. C. M. K.; Blokker, P.; Schogt, N.; Rijpstra, W. I. C.; Grice, K.; Baas, M.; Damsté, J. S. S. Biosynthetic effects on the stable carbon isotopic composition of algal lipids: implications for deciphering the carbon isotopic biomarker record. Geochim. Cosmochim. Acta, 1998, 62, 1397-1406, DOI: 10.1016/S0016-7037(98)000763

(23) Lang, I.; Hodac, L.; Friedl, T.; Feussner, I. Fatty acid profiles and their distribution patterns in microalgae: a comprehensive analysis of more than 2000 strains from the SAG culture collection. BMC Plant Biol., 2011, 11, DOI: 10.1186/1471-2229-11-124

(24) El Maghraby, D. M.; Fakhry, E. M. Lipid content and fatty acid composition of Mediterranean macro-algae as dynamic factors for biodiesel production. Oceanologia, 2015, 57, 86-92, DOI: 10.1016/j.oceano.2014.08.001

(25) Bigogno, C.; Khozin-Goldberg, I.; Boussiba, S.; Vonshak, A.; Cohen, Z. Lipid and fatty acid composition of the green oleaginous alga Parietochloris incisa, the richest plant source of arachidonic acid. Phytochemistry, 2002, 60, 497-503, DOI: 10.1016/S00319422(02)00100-0

(26) van Kuijk, F. J.; Thomas, D. W.; Konopelski, J. P.; Dratz, E. A. Transesterification of phospholipids or triglycerides to fatty acid benzyl esters with simultaneous methylation 
of free fatty acids for gas-liquid chromatographic analysis. J. Lipid Res. 1986, 27, 452456.

(27) Swanson, D.; Block, R.; Mousa, S. A. Omega-3 fatty acids EPA and DHA: health benefits throughout life. American Society for Nutrition. Adv. Nutr., 2012, 3, 1-7, DOI: 10.3945/an.111.000893

(28) Carroll, J. Exxon at least 25 Years Away From Making Fuel From Algae. Bloomberg Markets, 2013, March 8.

(29) Pinzi, S.; Garcia, I. L.; Lopez-Gimenez, F. J.; Luque de Castro, M. D.; Dorado, G.; Dorado, M. P. The ideal vegetable oil-based biodiesel composition: a review of social, economical and technical implications. Energy \& Fuels, 2009, 23, 2325-2341, DOI: $10.1021 /$ ef801098a

(30) Duke, J. A. Handbook of Energy Crops; Purdue University, 1983.

(31) van der Vossen H. A. M.; Mkamilo, G. S.; Lemmens, R. H. M. J.; Ozen, L. P. A. Eds. Plant Resources of Tropical Africa, Volume 14. Vegetable oils, PROTA Foundation, Backhuys Publishers, Wageningen, Netherlands, 2007.

(32) Robb, J. B.; Travis, P. D. The rise and fall of the gulf coast tung oil industry. Forest History Today, Spring/Fall, 2013, 14-22.

(33) Mietkiewska, E.; Lin, Y.; Weselake, R. J. Engineering production of C18 conjugated fatty acids in developing seeds of oil crops. Biocatal. Agric. Biotechnol., 2014, 3, 44-48, DOI: 10.1016/j.bcab.2013.11.003

(34) Cahoon, E. B.; Carlson, T. J.; Ripp, K. G.; Schweiger, B. J.; Cook, G. A.; Hall, S. E.; Kinney, A. J. Biosynthetic origin of conjugated double bonds: production of fatty acid 
components of high-value drying oils in transgenic soybean embryos. Proc. Natl. Acad.Sci., 1999, 96, 12935-12940, DOI: 10.1073/pnas.96.22.12935

(35) Vanhercke, T.; Wood, C. C.; Stymne, S.; Singh, S. P.; Green, A. G. Metabolic engineering of plant oils and waxes for use as industrial feedstocks. Plant Biotechnol. J., 2013, 11, 197-210, DOI: 10.1111/pbi.12023

(36) Vereshchagin, A. G.; Novitskaya, G. V. The triglyceride composition of linseed oil. $J$. Am. Oil Chem. Soc., 1965, 42, 970-974, DOI: 10.1007/BF02632457

(37) Food and agriculture data, 2014, http://www.fao.org/.

(38) Yang, B.; Kallio, H. P. Fatty acid composition of lipids in sea buckthorn (Hippophaë rhamnoides L.) berries of different origins. J. Agric. Food Chem., 2001, 49, 1939-1947, DOI: $10.1021 /$ jf001059s

(39) Fatima, T.; Snyder, C. L.; Schroeder, W. R.; Cram, D.; Datla, R.; Wishart, D.; Weselake, R. J.; Krishna, P. Fatty acid composition of developing sea buckthorn (Hippophae rhamnoides L.) berry and the transcriptome of the mature seed. PLoS One, 2012, 7, DOI: 10.1371/journal.pone.0034099.

(40) Chikkali, S.; Mecking, S. Refining of Plant Oils to Chemicals by Olefin Metathesis. Angew. Chem. Int. Ed. 2012, 51, 5802-5808, DOI: 10.1002/anie.201107645

(41) Mol, J. C. Application of olefin metathesis in oleochemistry: an example of green chemistry. Green Chem., 2002, 4, 5-13, DOI: 10.1039/B109896A

(42) Marinescu, S. C.; Schrock, R. R.; Müller, P.; Hoveyda, A. H. Ethenolysis reactions catalyzed by imido alkylidene monoaryloxide monopyrrolide (MAP) complexes of molybdenum. J. Am. Chem. Soc. 2009, 131, 10840-10841, DOI: 10.1021/ja904786y 
(43) Patel, J.; Elaridi, J.; Jackson, W. R.; Robinson, A. J.; Serelis, A. K.; Such, C. Crossmetathesis of unsaturated natural oils with 2-butene. High conversion and productive catalyst turnovers. Chem. Commun. 2005, 5546-5547, DOI: $10.1039 / \mathrm{b} 511626 \mathrm{k}$

(44) Tuba, R.; Al-Hashimi, M.; Bazzi, H. S.; Grubbs, R. H. One-pot synthesis of poly(vinyl alcohol) (PVA) copolymers via ruthenium catalyzed equilibrium ring-opening metathesis polymerization of hydroxyl functionalized cyclopentene. Macromolecules 2014, 47, 8190-8195, DOI: 10.1021/ma501976v

(45) Murdzek, J. S.; Schrock, R. R. Well-characterized olefin metathesis catalysts that contain molybdenum. Organometallics 1987, 6, 1373-1374, DOI: 10.1021/om00149a048

(46) Schrock, R. R.; Murdzek, J. S.; Bazan, G. C.; Robbins, J.; DiMare, M.; O’Regan, M. Synthesis of molybdenum imido alkylidene complexes and some reactions involving acyclic olefins. J. Am. Chem. Soc. 1990, 112, 3875-3886, DOI: 10.1021/ja00166a023

(47) Teng, X.; Cefalo, D. R.; Schrock, R. R.; Hoveyda, A. H. Enhancement of enantioselectivity by THF in asymmetric Mo-catalyzed olefin metathesis. Catalytic enantioselective synthesis of cyclic tertiary ethers and spirocycles. J. Am. Chem. Soc. 2002, 124, 10779-10784, DOI: 10.1021/ja020671s

(48) Nguyen, S. T.; Johnson, L. K.; Grubbs, R. H.; Ziller, J. W. Ring-opening metathesis polymerization (ROMP) of norbornene by a Group VIII carbene complex in protic media. J. Am. Chem. Soc. 1992, 114, 3974-3975, DOI: 10.1021/ja00036a053

(49) Sanford, M. S.; Ulman, M.; Grubbs, R. H. New insights into the mechanism of ruthenium-catalyzed olefin metathesis reactions. J. Am. Chem. Soc. 2001, 123, 749-750, DOI: $10.1021 / \mathrm{ja003582t}$ 
(50) Grubbs, R. H. Olefin metathesis. Tetrahedron, 2004, 60, 7117-7140, DOI: 10.1016/j.tet.2004.05.124

(51) Kovács, E.; Sághy, P.; Turczel, G.; Tóth, I.; Lendvay, G.; Domján, A.; Anastas, P. T.; Tuba, R. Metathesis of renewable polyene feedstocks - Indirect evidences of the formation of catalytically active ruthenium allylidene species. J. Organomet. Chem. 2017, 847, 213-217, DOI: 10.1016/j.jorganchem.2017.04.018

(52) Sun, D.; Yamada, Y.; Sato, S.; Ueda, W. Glycerol hydrogenolysis into useful C3 chemical. Appl. Catal., B, 2016, 193, 75-92, DOI: 10.1016/j.apcatb.2016.04.013

(53) Behr, A.; Toepell, S. Comparison of reactivity in the cross-metathesis of allyl acetatederivatives with oleochemical compounds. J. Am. Oil Chem. Soc. 2015, 92, 603-611, DOI: $10.1007 / \mathrm{s} 11746-015-2614-7$

(54) Kajetanowicz, A.; Sytniczuk, A.; Grela, K. Metathesis of renewable raw materialsinfluence of ligands in the indenylidene type catalysts on self-metathesis of methyl oleate and cross-metathesis of methyl oleate with (Z)-2-butene-1,4-diol diacetate. Green Chem., 2014, 16, 1579-1585, DOI: 10.1039/C3GC42194E

(55) Dinger, M. B.; Mol, J. C. Degradation of the second-generation Grubbs metathesis catalyst with primary alcohols and oxygen - Isomerization and hydrogenation activities of monocarbonyl complexes. Eur. J. Inorg. Chem. 2003, 2827-2833, DOI: 10.1002/ejic.200200702

(56) Tuba, R.; Grubbs, R. H. Ruthenium catalyzed equilibrium ring-opening metathesis polymerization of cyclopentene. Polym. Chem., 2013, 4, 3959-3962, DOI: 10.1039/C3PY00584D 
(57) Dereli, O.; Düz, B.; Imamoglu, Y. The $\mathrm{WCl}_{6}-\mathrm{e}^{-}-\mathrm{Al}-\mathrm{CH}_{2} \mathrm{Cl}_{2}$ catalyzed polypentenamer formation via ring-opening metathesis polymerization (ROMP). Eur. Polym. J., 2006, 42, 368-374, DOI: 10.1016/j.eurpolymj.2005.07.025

(58) Behr, A.; Gomes, J. P. The cross-metathesis of methyl oleate with cis-2-butene-1,4-diyl diacetate and the influence of protecting groups. Beilstein J. Org. Chem. 2011, 7, 1-8, DOI: $10.3762 /$ bjoc.7.1

(59) Öztürk, B. Ö.; Topoglu, B.; Şehitoglu, S. K. Metathesis reactions of rapeseed oil-derived fatty acid methyl esters induced by monometallic and homobimetallic ruthenium complexes. Eur. J. Lipid Sci. Technol. 2015, 117, 200-208, DOI: 10.1002/ejlt.201400342

(60) Porri, L.; Diversi., P.; Lucherini, A.; Rossi, R. Catalysts derived from ruthenium and iridium for the ring-opening polymerization of cycloolefins. Makromol. Chem. 1975, 176, 3121-3125, DOI: 10.1002/macp.1975.021761029

(61) Consorti, C. S.; Aydos, G. L. P.; Dupont, J. Tandem isomerisationmetathesis catalytic processes of linear olefins in ionic liquid biphasic system. Chem. Commun. 2010, 46, 9058-9060, DOI: 10.1039/c0cc03891a

(62) France, M. B.; Feldman, J.; Grubbs, R. H. An iridium-based catalyst system for metathesis/isomerization of acyclic olefins, including methyl oleate. J. Chem. Soc., Chem. Commun. 1994, 0, 1307-1308. DOI: 10.1039/C39940001307

(63) Pfister, K. F.; Baader, S.; Baader, M.; Berndt, S.; Gooßen, L. J. Biofuel by isomerizing metathesis of rapeseed oil esters with (bio)ethylene for use in contemporary diesel engines. Sci. $A d v . \mathbf{2 0 1 7}, 3$, DOI: 10.1126/sciadv.1602624.

(64) Ohlmann, D. M.; Tschauder, N.; Stockis, J.-P.; Gooßen, K.; Dierker, M.; Gooßen, L. J. Isomerizing olefin metathesis as a strategy to access defined distributions of unsaturated 
compounds from fatty acids. J. Am. Chem. Soc. 2012, 134, 13716-13729. DOI: $10.1021 / \mathrm{ja} 303822 \mathrm{cp}$

(65) Larock, R. C.; Dong, X.; Chung, S.; Reddy, C. K.; Ehlers, L. E. Preparation of conjugated soybean oil and other natural oils and fatty acids by homogeneous transition metal catalysis. J. Am. Oil. Chem. Soc., 2001, 78, 447-453. DOI: 10.1007/s11746-0010284-1 


\section{For Table of Contents Use Only}

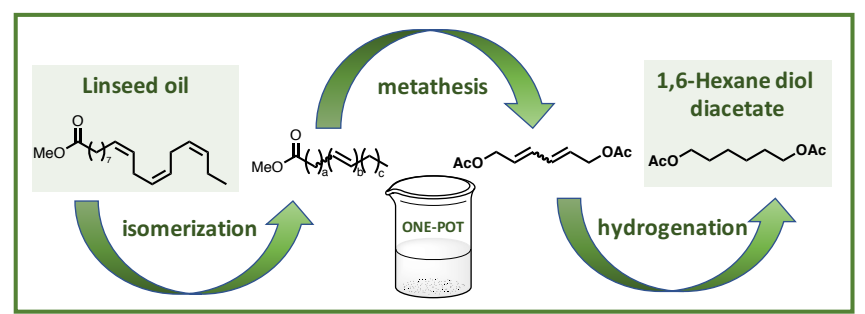

One pot isomerization, metathesis and hydrogenation of polyunsaturated vegetable oils provide a wide range of polyester and polyamide precursors. 